\title{
Listeria spp. E Listeria monocytogenes NA PRODUÇÃO DE SALSICHAS TIPO HOT DOG
}

\author{
Alessandra Paro Rodrigues Cesar ${ }^{1}$, Albenones José de Mesquita ${ }^{2}$, Cristiano Sales Prado ${ }^{2}$, Iolanda \\ Aparecida Nunes ${ }^{2}$, Edivaldo Sampaio de Almeida Filho ${ }^{3}$ \\ 1 - Médica Veterinária Fiscal Federal Agropecuário do Ministério da Agricultura, Pecuária e Abastecimento - \\ alessandra.cesar@agricultura.gov.br \\ 2 - Professores doutores, Escola de Veterinária e Zootecnia da Universidade Federal de Goiás. \\ 3 - Professor doutor de Inspeção de Produtos de Origem Animal da UFMT.
}

\begin{abstract}
RESUMO
Listeria monocytogenes está amplamente distribuída no ambiente e tem sido isolada de alimentos associados a surtos de elevada letalidade, representando um risco para a saúde pública. Em alguns países, os produtos prontos para consumo, como embutidos cozidos, entre os quais as salsichas, estão associadas à listeriose humana. Considerando a relevância do tema e a necessidade de dados, analisou-se a ocorrência de Listeria spp. e $L$. monocytogenes na produção de salsichas em dois estabelecimentos sob SIF, sendo que em um deles, as ferramentas de autocontrole estavam implantadas. Os resultados das análises microbiológicas de 106 amostras, entre matéria-prima cárnea, produto acabado e pools de swabs do ambiente pós-cozimento, quando submetidos ao

indicaram que 7 a $9 \%$ das salsichas continham $L$. monocytogenes. Obtiveram-se 88 isolados de $L$. monocytogenes a partir de 106 amostras, sendo que destas, 76 foram coletadas nas indústrias que participaram do experimento e 30 eram provenientes do varejo. Identificou-se $95 \%$ dos sorotipos como $4 \mathrm{~b}, 1 / 2 \mathrm{a}$ e $1 / 2 \mathrm{~b}$. Concluiu-se que além de apresentar fatores de risco desconhecidos quanto à presença desse patógeno nas salsichas consumidas no Brasil, a situação preocupa pela escassez de dados epidemiológicos, ausência de padrões e falta de informação ao consumidor, tanto no que diz respeito à possibilidade da presença de L. monocytogenes, especialmente para grupos de risco, como a importância do aquecimento antes do consumo.
\end{abstract} programa@Risk, apresentaram valores médios que

PALAVRAS-CHAVE: contaminação, embutido cozido, listeriose, salsicharia.

\section{Listeria spp. AND Listeria monocytogenes IN INDUSTRIAL PLANTS OF HOT DOG FRANKFURTERS}

Listeria monocytogenes is widely distributed in the environment and it has been isolated from food that were associated to outbreaks of high lethality in many countries. Thus, this bacterium represents an important pathogen to the public health. Ready-to-eat products, like cooked stuffed food, within them, frankfurters, are associated to human listeriosis in many countries. Taking into consideration the importance of the subject and the need of more data about it, the occurrence of Listeria spp. and L. monocytogenes in industrial plants, in meat raw materials, in slurry and frankfurters was investigated. These samples were collected in two production plants 
with SIF (Federal Inspection Service); in one of them GMP, HACCP and SOP were implemented. The results of the 106 microbiological analysis were submitted to the program@Risk to obtain the risk analysis; the mean values results showed that 7 to $9 \%$ of the frankfurters in the market may have L. monocytogenes. The analysis indicated that 88 strains of $L$. monocytogenes were obtained from 106 samples; among them, 76 were collected in the industrial plants that participate in the experiment, and 30 were collected in the market. In serological typification, $95 \%$ of these strains were classified as serotypes $4 \mathrm{~b}, 1 / 2 \mathrm{a}$ and $1 / 2 \mathrm{~b}$. Besides the presence of the bacterium in frankfurthers consumed in Brazil and the risk factors associated to this pathogen, the situation concerns because of the lack of epidemiological data, absence of patterns and the deficient information given to the consumer, specially information related to the presence of L. monocytogenes, particularly important to the groups at risk, as well as information related to the importance of heating the product.

KEY-WORDS: contamination, cooked stuffed food, listeriosis, industrial plant.

\section{INTRODUÇÃO}

Há seis espécies de Listeria conhecidas: $L$. monocytogenes, L. innocua, L. ivanovii, L. seeligeri, L. welshimeri e L. grayi; dessas, apenas L. monocytogenes é patogênica para o homem (FARBER \& PETERKIN, 1991; ROCOURT \& BUCHRIESER, 2007). Com base nos antígenos somáticos $(\mathrm{O})$ e flagelar $(\mathrm{H})$, L. monocytogenes está dividida em 13 sorotipos: 1/2a, 1/2b, 1/2c, 3a, 3b, 3c, 4a, 4ab, 4b, 4c, 4d, $4 \mathrm{e}$ e 7 (FSIS/USDA/CFSAN/FDA/USDHHS, 2003).

A temperatura ótima para multiplicação de $L$. monocytogenes é de $37^{\circ} \mathrm{C}$, porém, multiplica-se também sob refrigeração, não devendo esse método ser considerado eficaz para seu controle (HARMAYANI et al., 1993).

Segundo JAY (2005), L. monocytogenes é um patógeno intracelular, ubíquo e associado a doenças de origem alimentar e, de acordo com TERATANAVAT \& HOOKER (2004), responsável por diversas operações de recolhimento (recall) de alimentos. A listeriose é uma enfermidade bastante severa, podendo ocorrer na forma de surtos ou casos esporádicos (FARBER \& PETERKIN, 1991). A grande maioria (95\%) das infecções humanas por L. monocytogenes é causada pelos sorotipos $1 / 2 \mathrm{a}, 1 / 2 \mathrm{~b}$ e $4 \mathrm{~b}$ (GRAVES et al., 2007).

As elevadas taxas de mortalidade resultantes de listeriose variam de 20\% (GELLIN \& BROOME, 1989) a 30\% (ROCOURT, 1996; FISHER et al., 2000), sendo que a forma primária de transmissão do microrganismo ocorre por meio de alimentos (WHO, 1988; KATHARIOU, 2002).

Alguns estudos indicaram que certas partes de equipamentos, que são difíceis de higienizar, como esteiras, picadoras, fatiadoras e embaladoras, estavam entre os principais sítios de L. monocytogenes, mesmo após as operações de limpeza (MIETTINEN et al., 1999; AUTIO et al., 2000; TOMPKIN, 2002).

A prevalência e a incidência de $L$. monocytogenes em produtos comercializados prontos para o consumo tem sido objeto de estudo em diversos países (WILSON, 1995; UYTTENDAELE et al., 1999; AGUADO et al., 2001; GOMBAS et al., 2003; VAN COILLIE et al., 2004; VITAS \& GARCIA-JALON, 2004; ANGELIDIS \& KOUTSOUMANIS, 2006). Somente de 1986 a 1987, foram registrados $1600 \mathrm{ca}-$ sos de listeriose nos Estados Unidos da América (EUA), ocasionando 400 mortes e tendo como um dos alimentos envolvidos salsichas que não foram aquecidas antes do consumo (SCHWARTZ et al., 1988; GELLIN et al., 1991). A destruição da bactéria pelo calor depende do binômio tempo e temperatura. Segundo PORTO et al. (2004), reaquecendo as salsichas antes do consumo por $70^{\circ} \mathrm{C} / 2 \mathrm{~min}$ ou 80 a $90^{\circ} \mathrm{C} / 0,6 \mathrm{~min}$, há redução significativa de $L$. monocytogenes previamente inoculada.

No ambiente industrial, os microrganismos podem estar em suspensão (JAY, 2005), ou podem se organizar em comunidades na forma de biofilmes, que se fixam às superfícies (GANDHI \& CHIKINDAS, 2007). Algumas cepas de L. monocytogenes podem persistir no ambiente de processamento por longos períodos, havendo relatos de persistência até por mais de 10 anos (KATHARIOU, 2002; TOMPKIN, 2002); porém, os fatores relacionados à persistência ou não de L. monocytogenes no ambiente de processamento de alimentos ainda não são bem entendidos. Há sugestões de que essa persistência esteja relacionada com a habilidade de algumas cepas formarem biofilmes e assim resistirem aos sanitizantes (HOLAH et al., 2002). Para MORETRO \& LANGSRUD (2004), L. monocytogenes pode se estabelecer no ambiente industrial por anos, e a persistência está frequentemente associada à equipamentos ou ambientes de difícil higienização.

A adesão de L. monocytogenes pode ocorrer 
sobre vários tipos de superfícies (DONLAN, 2002). $\mathrm{Na}$ indústria de alimentos, as superfícies de equipamentos e de substâncias selantes impermeáveis, de cintas transportadoras e ralos são potenciais reservatórios de Listeria spp. (LADO \& YOUSEF, 2007).

Para minimizar a contaminação por $L$. monocytogenes em salsichas é importante identificar as fontes, as rotas e os isolados do patógeno nos estabelecimentos. As ferramentas de autocontrole Boas Práticas de Fabricação (BPF), Procedimentos Padrão de Higiene Operacional (PPHO) e Análise de Perigos e Pontos Críticos de Controle (APPCC), quando efetivamente implantadas pela indústria, constituem controles que minimizam os riscos associados à presença de L. monocytogenes nos alimentos (SHANK et al., 1996; REIJ \& DEN AANTREKKER, 2004).

No Brasil, dados sobre a ocorrência de L. monocytogenes em salsichas são escassos e as normas brasileiras vigentes não determinam que o fabricante faça constar no rótulo a necessidade de aquecimento ou fervura das mesmas antes do consumo. Portanto, as salsichas podem ou não ser reaquecidas antes do consumo, o que aumenta a complexidade do problema de controle do patógeno no país.

Embora L. monocytogenes não se multiplique em temperaturas menores que $-1,5^{\circ} \mathrm{C}$, a bactéria pode sobreviver em temperaturas muito baixas (ELKEST \& MARTH, 1991). O congelamento e a estocagem a $-18^{\circ} \mathrm{C}$ inativa 1 a $2 \log _{10}$ UFC da população e causa injúrias em mais de $50 \%$ das células (LADO \& YOUSEF, 2007). No entanto, repetições de congelamento e descongelamento causam o rompimento da membrana celular da bactéria permitindo o vazamento do conteúdo citoplasmático (EL-KEST \& MARTH, 1991; JAY, 2005).

Com este estudo, objetivou-se verificar a ocorrência de Listeria spp. e L. monocytogenes durante um turno de produção de salsichas em duas indústrias sob Serviço de Inspeção Federal (SIF), com realidades distintas, ou seja, com as ferramentas de autocontrole implantadas e ainda em implantação, bem como identificar a probabilidade de sua ocorrência em salsichas provenientes do varejo.

\section{MATERIAL E MÉTODOS}

Aplicou-se um questionário à inspeção local e à equipe do controle de qualidade de cada estabelecimento durante visita ao acaso, enfatizando tópicos contemplados pelas ferramentas de autocontrole (BPF, PPHO e APPCC) no âmbito da salsicharia.
Os estabelecimentos industriais foram codificados como 01 e 02 , e caracterizados de acordo com (i) identificação, (ii) volume de produção, (iii) data da colheita, (iv) tipo de salsicha e (v) implantação das ferramentas de autocontrole.

Em visita realizada ao acaso nos meses de setembro e outubro de 2007 , foram colhidas 36 amostras na indústria 01 e 40 amostras na indústria 02 , constituídas por pool de swabs ambientais de superfícies da área pós-cozimento e amostras de porções da matéria-prima cárnea, emulsão e do produto acabado, em períodos alternados ao longo da linha de produção de salsichas, conforme o fluxo de produção de cada estabelecimento. Já as amostras do varejo foram adquiridas em março de 2008, em oito supermercados da cidade de Goiânia-GO.

As amostras de alimentos nas indústrias foram colhidas aleatoriamente e em períodos distintos, ao longo da linha de produção de cada estabelecimento, em assepsia, na quantidade de 10 amostras de $500 \mathrm{~g}$ das carnes utilizadas como matéria-prima para a produção de salsichas, 10 amostras de $500 \mathrm{~g}$ de emulsão e 10 amostras do produto acabado, pronto para o consumo, todas resfriadas. Uma vez colhidas, acondicionadas em sacos de polipropileno esterilizados e identificadas, essas foram encaminhadas, sob refrigeração $\left(4^{\circ} \mathrm{C}\right)$, ao Laboratório de Microbiologia do Centro de Pesquisa em Alimentos da Escola de Veterinária e Zootecnia da Universidade Federal de Goiás (CPA/EVZ/UFG) para análise.

A colheita de swabs no ambiente de salsicharia ocorreu durante o desenvolvimento das atividades de produção, nas áreas pós-cozimento, sendo a quantidade estabelecida de acordo com a tecnologia e fluxo de produção empregada em cada indústria, gerando, portanto, diferença no número de amostras, sendo 06 pools de swabs na indústria 01 e 10 na indústria 02. Foram avaliadas superfícies de contato direto com o produto, tais como equipamentos e luvas dos manipuladores, e superfícies sem contato com o produto, a exemplo de ralos, paredes e aventais dos manipuladores.

A área para colheita nessas superfícies pré-estabelecidas foi de $100 \mathrm{~cm}^{2}$ e executada com auxílio de gabaritos previamente esterilizados. Os swabs foram umedecidos com água peptonada $0,1 \%$ (Difco) e transportados ao laboratório em tubos contendo 10 $\mathrm{mL}$ de água peptonada $0,1 \%$ e mantidos a $4^{\circ} \mathrm{C}$ até o momento da análise. Cada amostra constituiu-se de um pool, sendo dispostos três swabs de um mesmo tipo de superfície em cada tubo.

As amostras de salsichas no varejo foram co- 
lhidas em supermercados da cidade de Goiânia-GO, totalizando 30 amostras de salsichas procedentes das duas indústrias que participaram do experimento. No total, 11 amostras estavam embaladas e 19 foram compradas a granel (pesadas em unidades amostrais de $500 \mathrm{~g}$ ). Todas as salsichas amostradas apresentavam temperatura abaixo de $7^{\circ} \mathrm{C}$.

As amostras foram mantidas sob refrigeração, durante o transporte, utilizando-se caixa isotérmica e gelo reciclável, bem como em geladeira até o início das análises.

Utilizou-se como controle positivo de L. monocytogenes a cepa American Type Culture Collection, Instituto Adolfo Lutz (ATCC 7644-IAL), mantida em caldo LB adicionado de $50 \%$ de glicerol e renovadas mensalmente.

Utilizou-se o sistema VIDAS ${ }^{\circledR}$ como método rápido qualitativo (screening), após as etapas de enriquecimento primário e enriquecimento secundário, sendo que as amostras com resultados positivos foram submetidas à análise tradicional, preconizada pelo Ministério da Agricultura, Pecuária e Abastecimento, que inclui o isolamento em ágar sólido e provas confirmatórias.

Uma porção de $25 \mathrm{~g}$, obtida em pequenas frações de diversos pontos de cada unidade amostral, foi transferida assepticamente para $225 \mathrm{~mL}$ do caldo de enriquecimento primário UVM - Universidade de Vermont Modificado (Difco) adicionado de seu suplemento, homogeneizada por dois minutos em Stomacher (400 Blender, SE 11 PPUK, England), sendo a suspensão resultante incubada a $30^{\circ} \mathrm{C} \pm 1^{\circ} \mathrm{C}$ por 24h (BRASIL, 2003).

Após $24 \mathrm{~h}$, transferiu-se $1 \mathrm{~mL}$ da suspensão em caldo UVM para $10 \mathrm{~mL}$ do caldo Fraser (Difco), para enriquecimento secundário, suplementado com Fraser Broth Supplement (Difco), seguido de incubação a $30^{\circ} \mathrm{C} \pm 1^{\circ} \mathrm{C}$ por $24 \mathrm{~h}$ (BioMÉRIEUX, 2006a).

Após o enriquecimento secundário todas as amostras foram submetidas à análise imuno-enzimática no sistema automatizado VIDAS ${ }^{\circledR}$ (bioMérieux, Paris).

Utilizou-se o protocolo validado da Associação Francesa de Normalização (AFNOR) para detecção de Listeria spp. nas 106 amostras analisadas. Assim, após $24 \mathrm{~h}$, a $30^{\circ} \mathrm{C} \pm 1^{\circ} \mathrm{C}$ no caldo de enriquecimento secundário, transferiu-se $2 \mathrm{~mL}$ do material resultante para tubo esterilizado, que foi submetido a banho de água $\left(100^{\circ} \mathrm{C} / 15 \mathrm{~min}\right)$. Transferiu-se então uma alíquota de $0,5 \mathrm{~mL}$ do material já arrefecido para poço do barrete específico para Listeria spp. e submeteu-se a amostra à análise no sistema automa- tizado VIDAS ${ }^{\circledR}$ (bioMérieux, Paris). Os resultados foram apresentados impressos, como positivo ou negativo, em 45min. (BioMÉRIEUX, 2006b).

Para detecção de L. monocytogenes, foi utilizado o protocolo da Association of Official Analytical Chemists (AOAC) em todas as amostras analisadas anteriormente que apresentaram resultado positivo para Listeria spp. As etapas foram as mesmas utilizadas para Listeria spp., exceto que, para essa análise, as amostras não foram submetidas ao banho de água e os resultados qualitativos para $L$. monocytogenes emitidos em 70min (BioMÉRIEUX, 2006a).

As amostras positivas ao teste rápido, tanto para Listeria spp. como para L. monocytogenes, foram submetidas à protocolo convencional, estabelecido pela IN $N^{\circ} 62 / 2003$ do MAPA (BRASIL, 2003), para isolamento e identificação da bactéria. Para tanto, semearam-se por esgotamento em estrias, alíquotas de $1 \mu \mathrm{L}$ a partir do caldo Fraser inoculado, em Ágar Oxford Modificado - MOX (Difco) adicionado do suplemento antimicrobiano para o ágar MOX (BD - Becton, Dickinson), visando à obtenção de colônias presuntivas de Listeria spp. As placas foram incubadas invertidas a $35 \pm 1^{\circ} \mathrm{C}$ por $24-48 \mathrm{~h}$.

Nas divergências entre os resultados do teste rápido e do método convencional, repetiu-se o método convencional por quatro vezes, transferindo-se de 5 a 10 colônias suspeitas a partir do ágar MOX. Amostras com resultados negativos no método convencional foram plaqueadas em duplicata no ágar cromogênico Rapid' L mono (BioRad) a partir do caldo Fraser e de colônias suspeitas do agar MOX diluídas em solução salina a $0,85 \%$, sempre com a realização do controle positivo. Ressalte-se que os meios cromogênicos ainda não são utilizados no método oficial.

A purificação foi realizada em placas de ágar tripticase de soja - TSA (Difco) suplementado com $0,6 \%$ de extrato de levedura - YE (Oxoid), TSA-YE, por meio da inoculação de cinco a dez unidades formadoras de colônias enegrecidas típicas de Listeria spp. de cada placa de ágar MOX, após a observação suplementar, em microscopia de contraste de fase (Carl Zeiss, Alemanha), para visualização dos movimentos de tombamento, característicos de Listeria spp. Após incubação das placas a $30^{\circ} \mathrm{C} / 24 \mathrm{~h}$, as colônias resultantes foram examinadas sob iluminação transversal (transiluminação a $45^{\circ}$ ) para visualização de colônias azuladas de L. monocytogenes.

Colônias suspeitas foram semeadas por picada em profundidade e por estrias na superfície inclina- 
da de tubos com ágar TSI (Difco).

Para confirmação de Listeria spp., cinco a dez unidades formadoras de colônias suspeitas em TSAYE foram transferidas para tubos de ágar açúcar triplo e ferro - TSI (Difco) inclinado, cujas culturas, após $24 \mathrm{~h}$ de incubação a $35^{\circ} \mathrm{C}$, foram utilizadas para a realização das provas bioquímicas de produção de catalase, observação das características morfotintoriais (método de Gram), verificação de motilidade em meio semi-sólido (BBL/BD) e observação microscópica em contraste de fase (BRASIL, 2003).

Além das provas realizadas para identificação de Listeria spp., a confirmação de L. monocytogenes foi feita por verificação da produção de beta-hemólise em ágar sangue de carneiro a 5\%, capacidade de fermentação dos carboidratos ramnose (Sigma), xilose (Merck), maltose (Difco) e manitol (Synth), provas de VM e VP (Merck) e redução do nitrato (Vetec). Os métodos descritos também foram adotados para as análises dos swabs ambientais.

Colônias suspeitas de L. monocytogenes foram semeadas em estrias e por picada com agulha, logo abaixo da superfície do ágar sangue de carneiro a $5 \%$ (BRASIL, 2003). Após incubação a $35^{\circ} \mathrm{C} / 24$ $48 \mathrm{~h}$, consideraram-se como positivas as placas que apresentaram halo de hemólise total ( $\beta$-hemolíticas) ao redor da colônia.

Na prova do Gram, adicionou-se sobre lâmina de vidro $0,1 \mathrm{~mL}$ de hidróxido de potássio $3,5 \%$ e, em seguida, uma pequena porção de raspado da superfície do tubo com a cultura em teste. Após alguns segundos sob homogeneização em movimentos circulares contínuos com alça descartável, se não ocorria a formação de filamentos viscosos, a prova era considerada positiva para Listeria (MAC FADDIN, 1980).

A partir de resultados positivos para Listeria spp. em TSI com $24 \mathrm{~h}$, uma porção do cultivo bacteriano foi depositada sobre lâmina de vidro utilizando-se alça plástica esterilizada e uma gota de solução aquosa de peróxido de hidrogênio a 3\% (BRASIL, 2003) foi adicionada para a prova da catalase. O teste foi considerado positivo quando houve a formação de borbulhamento, associado ao desprendimento de $\mathrm{O}_{2}$ em função da presença da enzima catalase, sintetizada pelo microrganismo em estudo.

Para a redução do nitrato a nitrito, tubos de ensaio com $5 \mathrm{~mL}$ de caldo nitrato (Vetec) foram inoculados com pequena porção da cultura suspeita, utilizando-se alça plástica descartável esterilizada de $0,1 \mathrm{~mL}$ e incubados a $35^{\circ} \mathrm{C}$ por $24 \mathrm{~h}$ (BRASIL, 2003).
Ao final do período de incubação adicionou-se $1 \mathrm{~mL}$ da solução A (alfa-naftilamina $0,5 \%$ ) e $1 \mathrm{~mL}$ do reagente B (ácido sulfanílico $0,8 \%$ ) em $1 \mathrm{~mL}$ do caldo cultivado. A formação de coloração rósea ou avermelhada indica teste positivo.

No teste de Vermelho de Metila VM, adicionaram-se três gotas do reagente vermelho de metila $0,06 \%$ (Merck) à cultura incubada no caldo MR-VP (Merck) a $35^{\circ} \mathrm{C} / 96 \mathrm{~h}$. O aparecimento imediato de coloração vermelha foi indicativo de resultado positivo para a reação (BRASIL, 2003).

Na reação de Voges-Proskauer (VP), após incubação do inóculo em $1 \mathrm{~mL}$ do meio de Clark e Lubs (Merck) a $30^{\circ} \mathrm{C} / 48 \mathrm{~h}$, adicionou-se $0,6 \mathrm{~mL}$ de alfa-naftol $5 \%$ e $0,2 \mathrm{~mL}$ de solução de hidróxido de potássio $40 \%$. Após 30min de agitação dos tubos abertos, consideraram-se positivas as reações que apresentaram coloração avermelhada (BRASIL, 2003).

No teste de utilização de açúcares, porções de colônias suspeitas, isoladas com o auxílio de alça plástica descartável esterilizada, foram semeadas em tubos contendo caldo vermelho de fenol (Merck) adicionado dos açúcares ramnose, manitol, maltose e xilose previamente esterilizados a $121^{\circ} \mathrm{C} / 15 \mathrm{~min}$ (exceto a xilose que foi esterilizada por filtração -Milipore $0,10 \mu$ ). Tubos incubados a $30^{\circ} \mathrm{C}$ por 24 $36 \mathrm{~h}$ foram considerados positivos quando houve a acidificação do meio devido à fermentação dos açúcares, com alteração da cor vermelha do indicador vermelho de fenol para o amarelo (BRASIL, 2003).

Utilizando-se agulha plástica descartável esterilizada de $0,1 \mathrm{~mL}$, porções das culturas suspeitas foram inoculadas em linha reta por picada até dois terços do meio semi-sólido para teste de motilidade (BD). Após incubação a $25^{\circ} \mathrm{C} / 2$ por 5 dias, consideraram-se positivas as amostras que apresentaram crescimento na forma de "guarda-chuva" ou "chapéu-chinês", característico de bactérias do gênero Listeria, por evidenciar a preferência desse microrganismo pela microaerofilia (BRASIL, 2003).

Os isolados obtidos foram enviados ao Laboratório de Referência da Fundação Instituto Oswaldo Cruz (FIOCRUZ) para sorotipagem.

Além da análise descritiva, na avaliação das variáveis categóricas utilizaram-se o teste exato de Fisher e o teste de Qui-quadrado, aplicados de acordo com PIMENTEL GOMES (1987). Na análise de perigos, utilizou-se o software @Risk 4.5, PALISADE, versão 2005, empregando a distribuição de probabilidade contínua do tipo beta, para valores $0<\mathrm{x}<1$, com $99 \%$ de confiança apresentada no eixo 
$\mathrm{X}$ dos gráficos obtidos, sendo que o eixo $\mathrm{Y}$ corresponde à amostragem. Os resultados de presença ou ausência tanto para Listeria spp. como para L. monocytogenes, nas matrizes alimentares analisadas, foram processados pelo@Risk, com o intuito de se obter a variação de probabilidade de ocorrência da bactéria na produção amostrada.

\section{RESULTADOS E DISCUSSÃO}

De acordo com as respostas obtidas no questionário aplicado e a rotulagem utilizada, ambas as indústrias produzem salsichas do tipo hot dog, compostas por diferentes matérias-primas cárneas adicionadas de ingredientes misturados no cutter, até a formação da emulsão.

$\mathrm{Na}$ indústria 01 , as informações evidenciaram que as ferramentas de autocontrole (BPF, PPHO e APPCC) estavam implantadas na linha de produção de salsichas, com registros disponíveis para verificação. Entre os Pontos Críticos de Controle (PCCs) está a etapa de cocção, realizada em túnel de cozimento com injeção de vapor e com monitoramento contínuo da temperatura. Após as etapas de cozimento, quando atingiam a temperatura de $73^{\circ} \mathrm{C}$, e resfriamento a $15^{\circ} \mathrm{C}$, ambas em túnel, ocorria a remoção do envoltório, acidificação e embalagem primária a vácuo. Em seguida, as salsichas eram submetidas à pasteurização em tanque com água à temperatura de $85-90^{\circ} \mathrm{C} / 40 \mathrm{~min}$, resfriamento e armazenamento $\left(4^{\circ} \mathrm{C}\right)$. A separação física entre as áreas destinadas aos produtos crus e cozidos reduzia a possibilidade de contaminação cruzada.

Nas etapas de higienização, utilizavam-se diariamente água quente $\left(40-50^{\circ} \mathrm{C}\right)$, detergente alcalino e ácido peracético, sendo a amônia quaternária aplicada nos finais de semana. $\mathrm{O}$ uso de dois sanitizantes diferentes, empregados de forma alternada, segundo MEREGHETTI et al. (2000), pode ser benéfico no controle de Listeria spp.

A indústria 02 não havia ainda implantado as ferramentas de autocontrole, não havendo disponibilidade de registros para verificação. $\mathrm{O}$ tratamento térmico era realizado em estufa (40min) até atingir $74^{\circ} \mathrm{C}$ e em seguida as salsichas eram resfriadas por meio de aspersão de água clorada $(0,5$ a $1 \mathrm{ppm})$ em temperatura ambiente. Os envoltórios eram removidos de forma mecanizada e a acidificação era feita com ácido fosfórico $2 \%(\mathrm{pH} 2$ a 3). Em seguida, as salsichas eram embaladas manualmente, lacradas, pesadas e congeladas a $-12^{\circ} \mathrm{C}$. O tanque de acidificação/tingimento apresentava acabamento sanitário fa- lho, com a constatação de soldas aparentes, de difícil higienização.

No que diz respeito à separação física entre as áreas destinadas a produtos crus e cozidos, constatou-se a existência de contra-fluxo, pelo fato de a estufa possuir apenas uma porta utilizada como entrada e saída, como também pela localização do tanque de tingimento na sala de pesagem e preparo da emulsão de embutidos, o que poderia favorecer à contaminação pós-cozimento. Nesse aspecto, de acordo com o CODEX ALIMENTARIUS (2007), a introdução de L. monocytogenes no ambiente de preparo dos alimentos prontos para o consumo pode ser decorrente da insuficiente separação entre as áreas de produtos crus e produtos acabados, assim como pelo controle deficiente na circulacão de empregados.

O processo de higienização da salsicharia era realizado com água quente $\left(50^{\circ} \mathrm{C}\right)$, detergente alcalino e emprego diário de ácido peracético como sanitizante.

Conforme os dados apresentados na Tabela 1, entre as 30 amostras de alimentos colhidas na indústria 01, a matéria-prima cárnea e a emulsão apresentaram Listeria spp. em 9 (90\%) e $10(100 \%)$ das amostras, respectivamente. L. monocytogenes foi confirmada em $4(40 \%)$ amostras de carne e $2(20 \%)$ amostras de emulsão. Da sorotipagem dos 23 isolados de L. monocytogenes provenientes das 6 amostras positivas obtidas pelo método convencional, resultaram em 14 isolados com sorotipo $4 \mathrm{~b}, 8$ isolados com sorotipo $1 / 2 \mathrm{a}$ e um isolado com sorotipo $3 \mathrm{a}$.

No cômputo geral da indústria 01 , obtiveramse 25 isolados de L. monocytogenes, distribuídos os sorotipos 4b (71\%), 1/2a (28\%) e 3a (14\%), com predominância do sorotipo $4 \mathrm{~b}$ na base cárnea. A diferença entre os sorotipos identificados nas matrizes alimentares e no ambiente coincide com a informação de KATHARIOU (2002) de que a fonte primária de contaminação do alimento por $L$. monocytogenes está relacionada ao ambiente de processamento, o que pode justificar a não semelhança entre os sorotipos identificados.

O sorotipo $4 \mathrm{~b}$ da amostra ambiental (ralos) coincide com o da matéria-prima-cárnea que é proveniente de animais abatidos na própria indústria, como também adquiridos de terceiros. Os sorotipos $1 / 2$ a e 3a identificados na emulsão podem estar relacionados à adição de aditivos e outros ingredientes não-esterilizados, como corantes, estabilizantes, aromatizantes, proteína texturizada, amido, além da água, que não foram analisados de forma individua- 
lizada neste estudo. Apesar de não ser comum, há registros de ocorrência de surto de listeriose causado pelo sorotipo 3a, evidenciando sua importância em saúde pública (McLAUCHLIN et al., 2004). Em 1999, na Finlândia, foi registrado o provável primeiro surto de listeriose em decorrência da ingestão de manteiga pasteurizada, contaminada por esse sorotipo (LYYTIKÄINEN et al., 2000). Não é comum a presença do sorotipo 3 a nos estudos realizados no Brasil, havendo a necessidade de mais investigações.

TABELA 1 - Amostras positivas para Listeria spp. e L. monocytogenes segundo o sistema VIDAS® e segundo o método convencional com identificação dos sorotipos na indústria 01

\begin{tabular}{cccccc}
\hline & \multicolumn{2}{c}{$\begin{array}{c}\text { Listeria spp. } \\
\text { amostras positivas (\%) }\end{array}$} & $\begin{array}{c}\text { L. monocytogenes } \\
\text { amostras positivas (\%) }\end{array}$ & Sorotipo \\
\cline { 2 - 6 } Amostras analisadas (n) & VIDAS & Método conv. & VIDAS & Método conv. & \\
\hline Pool de Swabs (6) & $4(67 \%)^{*}$ & $4(67 \%)$ & $1(17 \%)$ & $1(17 \%)$ & $4 \mathrm{~b}$ \\
Matéria-prima cárnea (10) & $9(90 \%)$ & $9(90 \%)$ & $7(70 \%)$ & $4(40 \%)$ & $4 \mathrm{~b}$ \\
Emulsão (10) & $10(100 \%)$ & $10(100 \%)$ & $4(40 \%)$ & $2(20 \%)$ & $1 / 2 \mathrm{a} ; 3 \mathrm{a}$ \\
Produto acabado (10) & 0 & 0 & 0 & 0 & - \\
\hline Total (36) & $23(64 \%)$ & $23(64 \%)$ & $12(33 \%)$ & $7(19 \%)$ & \\
\hline
\end{tabular}

Como pode ser observado na Tabela 2, na indústria 02 , obtiveram-se 62 isolados de $L$. monocytogenes, provenientes das 12 amostras positivas obtidas pelo método convencional, que foram distribuídos em 33 sorotipos 1/2b (75\%), 28 sorotipos $1 / 2 \mathrm{a}(33 \%)$ e um sorotipo $1 / 2 \mathrm{c}(8 \%)$. Os sorotipos predominantes foram $1 / 2 \mathrm{~b}$ e $1 / 2 \mathrm{a}$, tanto no ambiente como na carne e na emulsão. Assim como na indústria 01 , a matéria-prima cárnea é produzida no próprio estabelecimento e também recebida de terceiros. A presença do sorotipo $1 / 2 \mathrm{c}$ na emulsão pode estar relacionada com a adição de ingredientes não-esterilizados.

A incidência de L. monocytogenes em produtos cárneos, registrados pelo programa de monitoramento norte americano e apresentados por FARBER et al. (2007), são de $18 \%$ para carne moída crua e 0 a $8 \%$ para produtos cárneos prontos para o consumo, sendo de $0,4-2,1 \%$ para salsichas de pequeno diâmetro e de $1,8-5,3 \%$ para as maiores.

Os resultados das análises das amostras de produtos acabados colhidos nas indústrias 01 e 02 não se assemelham aos dados obtidos por WALLACE et al. (2003), que em dois estabelecimentos produtores de salsichas, entre 27.300 amostras analisadas, $104(0,38 \%)$ continham L. monocytogenes.

TABELA 2 - Amostras positivas para Listeria spp. e L. monocytogenes no sistema VIDAS ${ }$ e no método convencional com identificação dos sorotipos na indústria 02

\begin{tabular}{lccccc}
\hline \multirow{2}{*}{ Amostras analisadas (n) } & \multicolumn{2}{c}{$\begin{array}{c}\text { Listeria spp. } \\
\text { amostras positivas (\%) }\end{array}$} & $\begin{array}{c}\text { L. monocytogenes } \\
\text { amostras positiva (\%) }\end{array}$ & \multirow{2}{*}{ Sorotipo } \\
\cline { 2 - 5 } & VIDAS & Método conv. & VIDAS & Método conv. & \\
\cline { 2 - 5 } Pool de Swabs (10) & $2(20 \%)^{*}$ & $2(20 \%)$ & $2(20 \%)$ & $2(20 \%)$ & $1 / 2 \mathrm{a} ; 1 / 2 \mathrm{~b}$ \\
Matéria-prima cámea (10) & $10(100 \%)$ & $10(100 \%)$ & $8(80 \%)$ & $8(80 \%)$ & $1 / 2 \mathrm{a} ; 1 / 2 \mathrm{~b}$ \\
Emulsão (10) & $9(90 \%)$ & $9(90 \%)$ & $2(20 \%)$ & $2(20 \%)$ & $1 / 2 \mathrm{a} ; 1 / 2 \mathrm{~b} ; 1 / 2 \mathrm{c}$ \\
Produto acabado (10) & 0 & 0 & 0 & 0 & - \\
\hline Total (40) & $21(52 \%)$ & $21(52 \%)$ & $12(30 \%)$ & $12(30 \%)$ & \\
\hline
\end{tabular}


A Tabela 3 apresenta os resultados para a ocorrência de L. monocytogenes no ambiente industrial pós-cozimento, nas matérias-primas cárneas e salsichas produzidas nos dois estabelecimentos amostrados, evidenciando a presença da bactéria no ambiente e na carne crua.

TABELA 3 - Pesquisa de L. monocytogenes no ambiente pós-cozimento, matérias-primas e salsichas tipo hot dog das indústrias 01 e 02

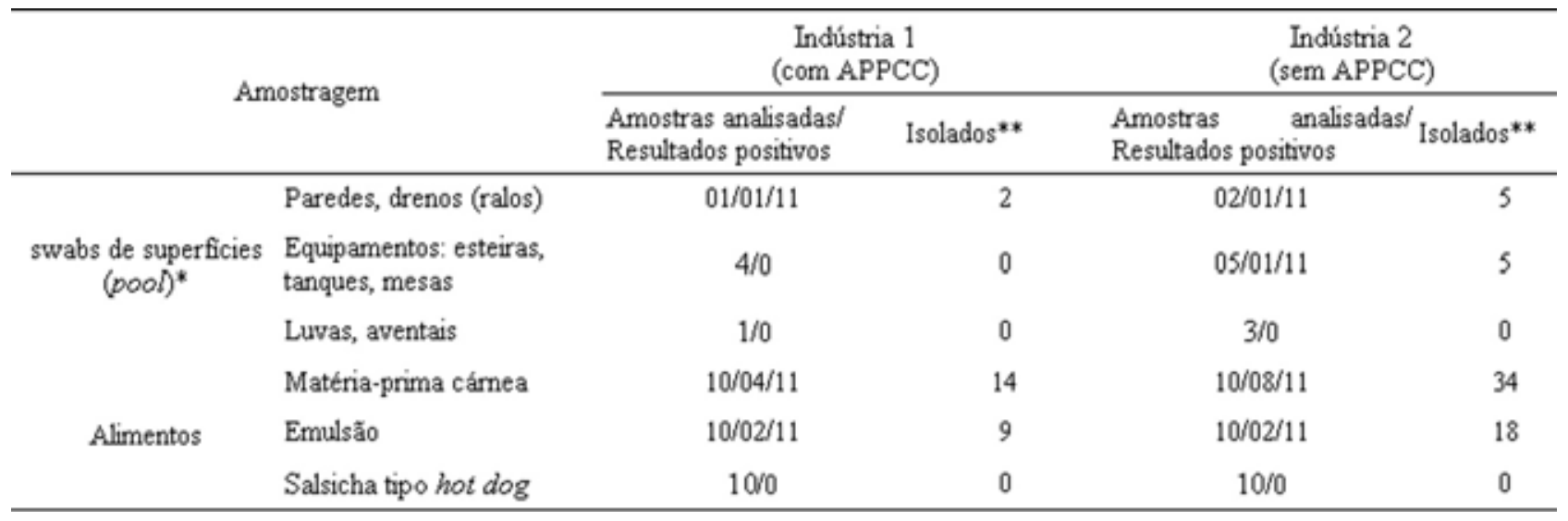

* cada 3 swabs compunham 1 amostra ** isolados identificados após sorotipagem

Quando da divergência de resultados entre a presença de $L$. monocytogenes no sistema VIDAS ${ }^{\circledR}$ e a ausência no método convencional, utilizou-se o meio cromogênico para visualização de colônias azuladas típicas da bactéria, constatando-se em determinadas situações a presença de raras colônias azuis. $O$ fato observado coincide com a sensibilidade descrita pelo método VIDAS ${ }^{\circledR}$ e com a dificuldade em se capturar colônias características de L. monocytogenes no método convencional quando há um número muito pequeno de colônias nas placas.

Como apresentado na Tabela 4, na indústria 01, as esteiras transportadoras nas saídas do forno de cozimento e do tanque de corante apresentaram Listeria spp. $\mathrm{Na}$ indústria 02, a presença de soldas com acabamento aparente que dificultam a higienização e as paredes do tanque de tingimento
(pH 2 a 3) apresentaram resultado positivo para $L$. monocytogenes. Os resultados coincidem com os de MIETTINEN et al. (1999) e de TOMPKIN (2002), de que certos equipamentos difíceis de higienizar, entre os quais as esteiras, apresentam maior possibilidade de se encontrar $L$. monocytogenes. Constatou-se, a partir dos resultados obtidos, que, nas áreas onde são manipuladas as salsichas após o cozimento, nas duas salsicharias, havia indícios de falhas no processo de higienização, seja pelas más condições das superfícies dos equipamentos, pela realização inadequada do processo de limpeza ou ainda pela possível existência de biofilmes, indicando a necessidade de se fazer $o$ acompanhamento das operações de higienização. A presença do patógeno no ambiente pós-cozimento gera a possibilidade de contaminação do produto final pronto para o consumo.

TABELA 4 - Superfícies amostradas nas indústrias 01 e 02 , com resultados positivos para Listeria spp. e $L$. monocytogenes

\begin{tabular}{|c|c|c|c|c|c|}
\hline $\begin{array}{l}\text { Pools de Swabs } \\
\text { Induistria } 01\end{array}$ & $\begin{array}{l}\text { VIDAS Listeria } \\
\text { spp. }\end{array}$ & $\begin{array}{l}\text { Méto do conv. } \\
\text { Listeria spp. }\end{array}$ & $\begin{array}{c}\text { VIDAS } \\
\text { L. monocytogenes }\end{array}$ & $\begin{array}{l}\text { Método conv. } \\
\text { L. monocytogenes }\end{array}$ & Sorotipo \\
\hline $\begin{array}{l}\text { Esteira após forno de } \\
\text { cozimento }\end{array}$ & + & + & . & - & \\
\hline Esteira pós-tingimento & + & + & - & - & \\
\hline Luvas manipuladores & + & + & . & . & \\
\hline Ralos & + & + & + & + & $4 b$ \\
\hline $\begin{array}{l}\text { Pools de Swabs } \\
\text { Indústria } 02\end{array}$ & $\begin{array}{l}\text { VIDAS }{ }^{\oplus} \text { Listeria } \\
\text { spp. }\end{array}$ & $\begin{array}{l}\text { Méto do conv. } \\
\text { Listeria spp. }\end{array}$ & $\begin{array}{l}\text { VIDAS } \\
\text { L. monocytogenes }\end{array}$ & $\begin{array}{l}\text { Método conv. } \\
\text { L. monocytogenes }\end{array}$ & Sorotipo \\
\hline Tanque corante & + & + & + & + & $1 / 2 \mathrm{a}$ \\
\hline Ralos & + & + & + & + & $1 / 2 \mathrm{a} ; 1 / 2 \mathrm{~b}$ \\
\hline
\end{tabular}


Neste aspecto, de acordo com o CODEX ALIMENTARIUS (2007), uma das estratégias para controlar a listeriose transmitida por alimentos consiste em introduzir um tratamento de mitigação adicional após o envase final, o que é observado na indústria 01 , que pasteuriza o produto após a embalagem primária.

A presença de L. monocytogenes nas instalações industriais sustenta a necessidade da existência e manutenção de programas de acompanhamento da presença desse patógeno por meio do monitoramento ambiental com frequência pré-estabelecida, especialmente nas superfícies de contato direto com o produto após o cozimento, evitando a recontaminação após o tratamento térmico.

De acordo com PETTINATI et al. (2006), os sorotipos $1 / 2 \mathrm{a}, 1 / 2 \mathrm{c}$ e $4 \mathrm{~b}$ já foram relacionados com surtos ou casos esporádicos de listeriose humana, não apenas no Brasil, mas em outros países. GARCÍA-ÁLVAREZ et al. (2006) e GRAVES et al. (2007) relataram que $95 \%$ das infecções humanas são causadas pelos sorotipos $1 / 2 \mathrm{a}, 1 / 2 \mathrm{~b}$ e $4 \mathrm{~b}$, detectados neste estudo aos níveis de $97,7 \%$; portanto, todos os sorotipos identificados são de importância em saúde pública.

Considerando-se os resultados das análises por categorias, observa-se que apesar do isolamento de Listeria spp. e L. monocytogenes nas amostras cárneas e nas instalações industriais, esse microrganismo não foi isolado no produto acabado. Embora a avaliação do tratamento térmico não tenha feito parte deste estudo, possivelmente tenha reduzido ou destruído a bactéria detectada na matéria-prima cárnea, comprovando a importância de monitorar o tempo e a temperatura de cozimento. Esses resultados são semelhantes aos obtidos por SAMELIS \& METAXOPOULOS (1999), que também não encontraram Listeria spp. em amostras de salsichas contaminadas por L. monocytogenes que foram submetidas à temperatura de $74^{\circ} \mathrm{C} / 4-5 \mathrm{~h}$. Da mesma forma, estudos de ANONYMOUS (1988), WENGER et al. (1990) e McKELLAR et al. (1994) enfatizam que o cozimento adequado durante a produção de salsichas elimina Listeria spp. que pode estar presente nas carnes utilizadas no preparo da emulsão, porém, a bactéria pode ser encontrada no produto final devido a falhas no processo de cocção ou em decorrência da contaminação pós-processamento. Assim, o fato de haver cozimento não mitiga a preocupação com o patógeno no ambiente de fábrica e em matérias-primas e ingredientes.

Além de as salsichas possuirem as características descritas pelo CODEX ALIMENTARIUS (2007), quanto à existência de fatores que contribuem para o risco de listeriose relacionada com alimentos prontos para o consumo, entre os quais a capacidade do alimento de favorecer a multiplicação de L. monocytogenes e a temperatura e o tempo de estocagem sob refrigeração, na formulação das salsichas, os estabelecimentos utilizam como conservantes nitrito e ou nitrato de sódio e sal, em concentrações que, de acordo com GLASS \& DOYLE (1989), não possuem ação inibitória sobre L. monocytogenes.

Nesse aspecto, experimentos de LE MARC et al. (2010), utilizando caldo TSB-YE (tripticase e soja acrescido de $0,6 \%$ de extrato de levedura), demonstraram que concentrações de cloreto de sódio de até $12,5 \%$ não foram suficientes para impedir a multiplicação de L. monocytogenes - ressalte-se que na grande maioria dos produtos cárneos, os teores de sal não ultrapassam 3,5\%.

Quanto à ação de diferentes concentrações de nitrito sobre L. monocytogenes, NGUTTER \& DONNELLY (2003) e NYACHUBA et al. (2007) verificaram que houve sobrevivência do patógeno mesmo com níveis residuais de 200ppm. Portanto, o limite máximo estabelecido pelos órgãos regulamentadores (BRASIL, 1999; BRASIL 2007) de $150 \mathrm{mg} / \mathrm{kg}$ para o emprego de nitrito de sódio em carnes e produtos cárneos não seria suficiente para impedir a multiplicação da bactéria no alimento que, segundo GLASS \& DOYLE (1989), mesmo quando associados, cloreto de sódio e sais de cura não impedem a multiplicação da bactéria. Conclui-se que há necessidade do controle do cozimento, utilizando-se as ferramentas de autocontrole.

Portanto, quando o patógeno, mesmo em pequena quantidade, está presente nesse alimento, conservado sob temperaturas de refrigeração, ele pode se multiplicar durante o período de validade e oferecer risco aos consumidores, principalmente àqueles que fazem parte do grupo de risco e que não dispõem de informações acerca da possibilidade da presença da bactéria nesse tipo de produto.

A análise categorizada dos resultados das análises microbiológicas realizadas indica que a contaminação da base cárnea e emulsão por $L$. monocytogenes na indústria onde estavam implantadas as ferramentas de autocontrole foi menor $(p<0,05)$ do que na indústria onde os referidos con- 
troles não eram realizados. Porém, não houve diferença $(\mathrm{p}>0,05)$ quanto à presença de L. monocytogenes no ambiente industrial pós-cozimento, com indícios de que as falhas estariam no PPHO.

Devido à patogenicidade de L. monocytogenes, bem como sua capacidade de formar biofilmes, a ocorrência desse microorganismo na matéria-prima e nas instalações demonstra a necessidade de reavaliação e intensificação das ferramentas de autocontrole implantadas na indústria 01 , em especial ao PPHO relacionado à higienização, bem como sua implantação na indústria 02 , buscando garantir a segurança dos produtos cárneos desses estabelecimentos. Situação semelhante de reavaliação de planos foi descrita por FARBER et al. (2007), quando em 2002, após investigação de surto de listeriose nos Estados Unidos, o FSIS concluiu que alguns estabelecimentos não contemplavam de forma correta em seus planos HACCP e Procedimentos Padrão de Higiene Operacional (SSOP) a probabilidade de contaminação de seus produtos por L. monocytogenes.

De acordo com o CODEX ALIMENTARIUS (2007), um elemento eficaz da gestão desse risco é a aplicacão de um programa de vigilância para avaliar o controle do ambiente a que se expõem os alimentos prontos para o consumo antes do envase final.

A natureza ubiquitária desse patógeno é evidenciada pela elevada taxa de contaminação observada nos produtos crus e no ambiente industrial; portanto, a elevada frequência de Listeria spp. encontrada implica risco para a produção, uma vez que, segundo SILVA et al. (2004), a elevada ocorrência de Listeria spp. pode indicar uma maior probabilidade de ocorrência de L. monocytogenes, constituindo-se, assim, num fator indicativo de risco à segurança do alimento.

A Tabela 5 mostra a ocorrência de Listeria spp e L. monocytogenes nas amostras de salsichas adquiridas no varejo. Os dados obtidos coincidem com os achados de ANONYMOUS (1993), quanto à Listeria spp., que nos Estados Unidos, entre 30 amostras de salsichas adquiridas no varejo, 20\% continham Listeria spp. sendo 17\% L. monocytogenes.

Os resultados revelam elevada ocorrência de Listeria spp. nas salsichas comercializadas a granel, após manipulação para fracionamento no estabelecimento comercial, além de L. monocytogenes, evidenciando falhas higiênico-sanitárias no ambiente fracionador.

Por outro lado, a presença de Listeria spp. em amostras embaladas, íntegras, que não foram manipuladas no varejo e que foram pasteurizadas após a embalagem na indústria, indica a possibilidade de células bacterianas de Listeria spp. terem resistido ao tratamento térmico ou estarem associadas à contaminação pós-cozimento.

Esses resultados não se assemelham aos achados de PETTINATI et al. (2006), que detectaram $L$. monocytogenes em 55,4\% das amostras de salsichas tipo "hot dog" comercializadas embaladas, não fracionadas, e adquiridas em supermercados da cidade de São Paulo, porém, sem indicação se as mesmas possuíam registro no SIF. Por outro lado, assemelham-se, estatisticamente, aos dados apresentados por VORSTER et al. (1993) que encontraram 8\% de Listeria spp. em salsichas Viena e não encontraram L. monocytogenes.

TABELA 5 - Ocorrência de Listeria spp. e L. monocytogenes pelo método VIDAS® e método convencional em salsichas adquiridas no varejo

\begin{tabular}{lccccc}
\hline \multicolumn{1}{c}{$\begin{array}{c}\text { Amostras } \\
\text { Salsichas (n) }\end{array}$} & \multicolumn{2}{c}{$\begin{array}{c}\text { Listeria spp. } \\
\text { amostras positivas }\end{array}$} & \multicolumn{3}{c}{$\begin{array}{c}\text { L. monocytogenes } \\
\text { amostras positivas }\end{array}$} \\
\hline & VIDAS & Método conv. & VIDAS & Método conv. & Sorotipo \\
Embaladas (11) & $3(27 \%)$ & $3(27 \%)$ & $0($ zero) & 0 (zero) & - \\
Granel (19) & $14(73 \%)$ & $14(73 \%)$ & $3(16 \%)$ & $1(5 \%)$ & $4 \mathrm{~b}$ \\
\hline Total (30) & $17(56 \%)$ & $17(56 \%)$ & $3(10 \%)$ & $1(3 \%)$ & \\
\hline
\end{tabular}

A análise estatística dos resultados apresenta a distribuição da probabilidade da ocorrência de Listeria spp. e L. monocytogenes nos lotes amostrados, tanto da matéria-prima cárnea, emulsão, como das salsichas adquiridas na indústria como no varejo.

Os resultados da análise evidenciam as eleva- 
das probabilidades de contaminação, possibilitando a adoção de medidas imediatas, como a revisão dos procedimentos operacionais nos estabelecimentos durante a produção, inclusive no que diz respeito à avaliação e utilização da matéria-prima cárnea (Tabelas 6 e 7).

TABELA 6 - Probabilidade de ocorrência de Listeria spp. e L. monocytogenes nos lotes amostrados nas indústrias 01 e 02 e em salsichas procedentes das indústrias 01 e 02 colhidas no varejo (@Risk 99\% de confiança)

\begin{tabular}{ccrcrc}
\hline \multirow{2}{*}{$\begin{array}{c}\text { Matriz } \\
\text { analisada }\end{array}$} & \multicolumn{2}{c}{ Indústria 01 } & \multicolumn{2}{c}{ Indústria 02 } \\
\cline { 3 - 6 } & Bisteria spp. & L. monocytogenes & Listeria spp. & L. monocytogenes \\
\hline \multirow{3}{*}{ Indústrias } & $53,00 \%$ & $13,00 \%$ & $66,00 \%$ & $43,00 \%$ \\
& Emulsão & $66,00 \%$ & $4,00 \%$ & $53,00 \%$ & $4,00 \%$ \\
\multirow{2}{*}{ Varejo } & Salsicha & $8 \%^{*}$ & $8 \%^{*}$ & $8 \%^{*}$ & $8 \%^{*}$ \\
& Salsicha Embalada & $5,00 \%$ & $9 \%^{*}$ & $2,00 \%$ & $10 \%^{*}$ \\
& Salsicha Granel & $46,00 \%$ & $1,00 \%$ & $17,00 \%$ & $7 \%^{*}$ \\
\hline
\end{tabular}

TABELA 7 - Probabilidade de ocorrência de Listeria spp. e L. monocytogenes em salsichas procedentes das indústrias 01 e 02 colhidas no varejo (@Risk 99\% de confiança)

\begin{tabular}{ccc}
\hline $\begin{array}{c}\text { Salsicha } \\
\text { (varejo) }\end{array}$ & \multicolumn{2}{c}{ Indústria 01 e 02 } \\
& Listeria spp. & L. monocytogenes \\
\hline Embalada & $8,00 \%$ & $7 \%^{*}$ \\
Granel & $47,00 \%$ & $1,00 \%$ \\
\hline * valor médio & &
\end{tabular}

Os dados suscitam a discussão acerca das condições microbiológicas da matéria-prima cárnea destinada à composição de produtos cozidos, tendo a etapa do tratamento térmico como ponto crítico de controle que torna aparentemente dispensável o controle da matéria-prima, especialmente face à característica ubiquitária da bactéria. Porém, ressaltese que as mesmas provêm de estabelecimentos onde os autocontroles também devam estar implantados na linha de produção do abate e que o cozimento de produtos com elevada contaminação por L. monocytogenes pode não ser letal para todas as células presentes.

\section{CONCLUSÕES}

Listeria spp. e sorotipos de L. monocytogenes foram detectados durante a produção de salsichas em duas indústrias sob SIF, evidenciando a necessidade de revisão dos Programas existentes na indús- tria 01 e implantação/implementação na indústria 02. Mesmo com a necessidade de reavaliação, no estabelecimento onde as ferramentas de autocontrole (BPF, PPHO e APPCC) estavam implantadas, identificou-se menor frequência de L. monocytogenes na matéria-prima cárnea utilizada no preparo de salsichas, ressaltando a importância do controle contínuo, com cumprimento dos monitoramentos e verificações pré-estabelecidos. A definição de padrões microbiológicos e a implantação imediata de programa de monitoramento específico por parte dos órgãos regulamentadores e fiscalizadores para controle de Listeria spp. e L. monocytogenes nessa categoria de produtos possibilitariam maior segurança em sua industrialização.

L. monocytogenes, sorotipo $4 \mathrm{~b}$, estava presente em amostra de salsicha com registro no SIF, comercializada a granel, em supermercado da cidade de Goiânia, o que possibilita concluir que a manipulação para granelização deveria ser permitida apenas em condições especiais, onde houver práticas sanitárias que garantam a segurança do alimento.

Salsichas com rotulos registrados no SIF comercializadas tanto a granel como em embalagens fechadas desde a indústria continham Listeria spp. evidenciando falhas no processo de produção.

Informações no rótulo do produto sobre a necessidade de aquecimento antes do consumo e maior interação entre órgãos regulamentadores e consumidores podem contribuir para evitar ou reduzir casos de listeriose. 


\section{AGRADECIMENTOS}

A toda a equipe do Centro de Pesquisas em Alimentos - CPA da Escola de Veterinária da UFG.

Aos Professores da UNB, Ângela Patrícia Santana e Vitor Gonçalves, pelo auxílio na análise dos dados.

\section{REFERÊNCIAS}

AGUADO, V.; VITAS, A.I.; GARCÍA-JALON, I. Random amplified polymorphic DNA typing applied to the study of cross-contamination by Listeria monocytogenes in processed food products. Journal of Food Protection, Ames, v.64, n.5, p.716-720, 2001.

ANGELIDIS, A.S.; KOUTSOUMANIS, K. Prevalence and concentration of Listeria monocytogenes in sliced ready-to-eat meat products in the Hellenic retail market. Journal of Food Protection, Ames, v.69, n.4, p.938-942, 2006.

ANONYMOUS. Listeria destruction in cooked meat products ineffective. Food Chemical News, Washington, v.30, n.15, p.32-34, 1988.

ANONYMOUS. Listeria found in $20 \%$ of hot dogs in L.A. times survey. Food Chemical News, Washington, v.35, n.21, p.45-46, 1993.

AUTIO, T.; SÄTERI, T.; FREDRIKSSON-AHOMAA, M.; RAHKIO, M.; LUNDÉN, J.; KORKEALA. H. Listeria monocytogenes contamination pattern in pig slaughterhouses. Journal of Food Protection, Ames, v.63, n.10, p.1438-1442, 2000.

BioMÉRIEUX. REF 30704 VIDAS® Listeria monocytogenes II (LMO2). 2006a. Disponível em http://www.afnor-validation.com/Certificates/ BIOMERIEUX/BIO\%2012-9\%2007-02\%20(en).pdf. Acesso em julho 2009.

BioMÉRIEUX. REF 30700 VIDAS® Listeria (LIS). 2006b. http://www.afnor-validation.com/Certificates/ BIOMERIEUX/BIO\%2012-2\%2006-94\%20(en).pdf. Acesso em julho 2009.

BRASIL, Ministério da Agricultura, Pecuária e Abastecimento. Gabinete do Ministro - MAPA. Instrução Normativa $\mathrm{N}^{\circ} 51$, de 29 de dezembro de 2006. Adota o Regulamento Técnico de atribuição de aditivos e seus limites das seguintes categorias de alimentos 8: carne e produtos cárneos. Diário Oficial da União, Brasília, DF, p.14, de 04 de janeiro de 2007. Seção 1. 2007.

BRASIL, Ministério da Agricultura, Pecuária e Abastecimento. Secretaria de Defesa Agropecuária - MAPA/SDA. Instrução Normativa $\mathrm{N}^{\circ} 62$ de 26 de agosto de 2003. Oficializa os Métodos Analíticos Oficiais para Análises Microbiológicas para Controle de Produtos de Origem Animal e Água. Diário Oficial da União, Brasília, DF, p.14, de 18 de setembro de 2003. Seção 1. 2003
BRASIL, Ministério da Saúde. Secretaria de Vigilância Sanitária - SVS/MS. Portaria $n^{\circ}$ 1004, de 11 de dezembro de 1998. Aprova o Regulamento Técnico: "Atribuição de Função de Aditivos, Aditivos e seus Limites Máximos de uso para a Categoria 8 - Carne e Produtos Cárneos". Diário Oficial da União, Brasília, DF, 54-E, 22 de março de 1999.

CODEX ALIMENTARIUS - Normas Oficiales del Codex - Directrices sobre la aplicación de principios generales de higiene de los alimentos para el control de Listeria monocytogenes en los alimentos CAC/GL 61 2007. $21 \mathrm{p}$.

DONLAN, R.M. Biofilms: microbial life on surfaces. Emerging Infectious Diseases, Atlanta, v.8, n.9, p.881$890,2002$.

EL-KEST, S.E.; MARTH, E.H. Injury and death of frozen Listeria monocytogenes as affected by glycerol and milk components. Journal of Dairy Science, v. 74, n.4, p.1201-1208, 1991.

FARBER, J.M.; PAGOTTO, F.; SCHERF, C. Incidence and behavior of Listeria monocytogenes in meat products. In: RYSER, E.T.; MARTH E.H. Listeria, Listeriose, and Food Safety. 3.ed. Boca Raton: CRC Press Taylor \& Francis Group, 2007. cap. 13, p.503-570.

FARBER, J.M.; PETERKIN, P.I. Listeria monocytogenes, a Food-Borne Pathogen. Microbiological Reviews, Washington, v.55, n.3, p.476-511, 1991.

FISHER, C.W.; LEE, D.; DODGE, B-A.; HAMMAN, K.M.; ROBINS, J.B.; MARTIN, S.E. Influence of catalase and superoxide dismutase on ozone inactivation of Listeria monocytogenes. Applied and Environmental Microbiology, Washington, v.66, n.4, p.1405-1409, 2000.

FSIS/USDA/CFSAN/FDA/USDHHS - Food Safety and Inspection/United States Department of Agriculture Service/United States Department of Health and Human Services/Food and Drug Administration's/Center for Food Safety and Applied Nutrition. Quantitative Assessment of the Relative Risk to Public Health from Foodborne Listeria monocytogenes Among Selected Categories of Readyto-Eat Foods, September, 2003. 540p. Disponível em: http://www.fda.gov/downloads/food/scienceresearch/resea rchareas/riskassessmentsafetyassessment/ucm197330.pdf. Acesso em julho 2009.

GANDHI, M.; CHIKINDAS, M.L. Listeria: A foodborne pathogen that knows how to survive. International Journal of Food Microbiology, Amsterdam, v.113, n. 1, p.1-15, 2007.

GARCÍA-ÁLVAREZ, M.; CHAVES, F.; SANZ, F.; OTERO, J.R. Epidemioligía molecular de las infecciones por Listeria monocytogenes em um área de Madrid durante um período de 3 años (2001-2003). Enfermedades Infecciosas y Microbiología Clínica, v.24, n.02, p.86-89, 2006.

GELLIN, B.G.; BROOME, C.V. Listeriosis. Journal of 
the American Medical Association, Chicago, v.261, n.9, p.1313-1320, 1989.

GELLIN, B.G.; BROOME, C.V.; BIBB, W.F.; WEAVER, R.E.; GAVENTA, S.; MASCOLA, L. \& LISTERIOSIS STUDY GROUP. The Epidemiology of Listeriosis in the United States-1986. American Journal of Epidemiology, Oxford, v.133, n.4, p.392-401, 1991.

GLASS, K.A.; DOYLE, M.P. Fate and thermal inactivation of Listeria monocytogenes in beaker sausage and pepperoni. Journal of Food Protection, Ames, v.52, n.4, p.226-231, 235, 1989.

GOMBAS, D.E.; CHEN, Y.; CLAVERO, R.S.; SCOTT, V.N. Survey of Listeria monocytogenes in ready-to-eat foods. Journal of Food Protection, Ames, v.66, n.4, p.559-569, 2003.

GRAVES, L.M.; SWAMINATHAN, B.; HUNTER, S.B. Subtyping Listeria monocytogenes. In: RYSER, E.T.; MARTH E.H. Listeria, Listeriose, and Food Safety. 3.ed. Boca Raton: CRC Press Taylor \& Francis Group, 2007. cap. 6, p.157-213.

HARMAYANI, E.; SOFOS, J.N.; SCHMIDT, G.R. Fate of Listeria monocytogenes in raw and cooked ground beef with meat processing additives. International Journal of Food Microbiology, Amsterdam, v.18, n.3, p.223232, 1993.

HOLAH, J.T.; TAYLOR, J.H.; DAWSON, D.J.; HALL, K.E. Biocide use in the food industry and the desinfectante resistance of persistent strains of Listeria monocytogenes and Escherichia coli. Journal of Applied Microbiology, Oxford, v.92, p.111S-120S, 2002.

JAY, J.M. Microbiologia de Alimentos, 6.ed. Porto Alegre: Artmed, 2005. 711p.

KATHARIOU, S. Listeria monocytogenes virulence and pathogenicity, a food safety perspective. Journal of Food Protection, Ames, v.65, n.11, p.1811-1829, 2002.

LADO, B.H.; YOUSEF, A.E. Characteristics of Listeria monocytogenes important to food processors. In: RYSER, E.T.; MARTH E.H. Listeria, Listeriose, and Food Safety. 3.ed. Boca Raton: CRC Press Taylor \& Francis Group, 2007. cap. 6, p.157-213.

LE MARC, Y.; SKANDAMIS P.N.; BELESSI, C.I.; MERKOURI, S.I.; GEORGE, S.M.; GOUNADAKI, A.S.; SCHVARTZMAN, S.; JORDAN, K.; DROSINOS, E.H.; BARANYI, J. Modeling the effect of abrupt acid and osmotic shifts within the growth region and across growth boundaries on adaptation and growth of Listeria monocytogenes. Applied and Environmental Microbiology, Washington, v.76, n.19, p.6555-63, 2010.

LYYTIKÄINEN, O.; AUTIO, T.; MAIJALA, R.; RUUTU, P.; HONKANEN-BUZALSKI, T.; MIETTINEN, M.; HATAKKA, M.; MIKKOLA, J.; ANTTILA, V.J.; JOHANSSON, T.; RANTALA, L.; AALTO, T.; KORKEALA, H. ; SIITONEN, A. An Outbreak of Listeria mo- nocytogenes serotype 3 a infections from butter in Finland. The Journal of Infectious Diseases, Chicago, v.181, n.5, p.1838-1841, 2000.

MAC FADDIN, J.F. Biochemical tests for identification of medical bacteria. 2.ed. Baltimore: Williams \& Wilkins, 1980. 527p.

McKELLAR, R.C; MOIR, R.; KALAB, M. Factors influencing the survival and growth of Listeria monocytogenes on the surface of Canadian retail wieners. Journal of Food Protection, Ames, v.57, n.5, p.387-392, 1994.

McLAUCHLIN, J.; MITCHELL, R.T.; SMERDON, W.J.; JEWELL, K. Listeria monocytogenes and listeriosis: a review of hazard characterization for use in microbiological risk assessment of foods. International Journal of Food Microbiology, Amsterdam, v.92, n.1, p.15-33, 2004.

MEREGHETTI, L.; QUENTIN, R.; MARQUET-VAN DER MEE, N.; AUDURIER, A. Low sensitivity of Listeria monocytogenes to quaternary ammonium compounds. Applied and Environmental Microbiology, Washington, v.66, n.11, p.5083-5086, 2000.

MIETTINEN, M.K.; BJÖRKROTH, K.J.; KORKEALA, H.J. Characterisation of Listeria monocytogenes from an ice-cream plant by serotyping and pulsed-field gel electrophoresis. International Journal of Food Microbiology, Amsterdam, v.46, n.3, p.187-192, 1999.

MORETRO, T.; LANGSRUD, S. Listeria monocytogenes: biofilm formation and persistence in food-processing environments. Biofilms, London, v.1, p.107-121, 2004.

NGUTTER, C.; DONNELLY, C. Nitrite-induced injury of Listeria monocytogenes and the effect of selective versus nonselective recovery procedures on its isolation from frankfurters. Journal of Food Protection, Ames, v.66, n.12, p.2252-7, 2003.

NYACHUBA, D.G.; DONNELLY, C.W.; HOWARD, A.B. Impact of nitrite on detection of Listeria monocytogenes in selected ready-to-eat (RTE) meat and seafood products. Journal of Food Science, Chicago, v.72, n.7, p.267-75, 2007.

PETTINATI, N.N.; TELLES, E.O.; BALLIAN, S.C. Listeria monocytogenes in hot dog sausages obtained from groceries stores on the city of São Paulo - a comparative and retrospective analysis of human listeriosis isolates. Veterinária e Zootecnia, Botucatu, v.13, n.2, p.182-191, 2006.

PIMENTEL GOMES, F. A estatística moderna na pesquisa agropecuária. 3.ed. Piracicaba: POTAFOS, 1987. $162 \mathrm{p}$.

PORTO, A.C.S.; CALL, J.E.; LUCHANSKY, J.B. Effect of reheating on viability of a five-strain mixture of Listeria monocytogenes in vacuum-sealed packages of frankfurters following refrigerated or frozen storage. Journal 
of Food Protection, Ames, v.67, n.1, p.71-76, 2004.

REIJ, M.W.; DEN AANTREKKER, E.D. Recontamination as a source of pathogens in processed foods. International Journal of Food Microbiology, Amsterdam, v.91, n.1, p.1-11, 2004.

ROCOURT, J. Risk factors for listeriosis. Food Control, v.7, n.4, p.195-202, 1996.

ROCOURT, J.; BUCHRIESER, C. The genus Listeria and Listeria monocytogenes: phylogenetic position, taxonomy, and identification. In: RYSER, E.T.; MARTH E.H. Listeria, Listeriose, and Food Safety. 3.ed. Boca Raton: CRC Press Taylor \& Francis Group, 2007. cap 1, p.1-20.

SAMELIS, J.; METAXOPOULOS, J. Incidence and principal sources of Listeria spp. And Listeria monocytogenes contamination in processed meats and a meat processing plant. Food Microbiology, London, v.16, n.5, p.465-477, 1999.

SCHWARTZ, B.; CIESIELSKI, C.A.; BROOME, C.V.; GAVENTA, S.; BROWN, G.R.; GELLIN, B.G.; HIGHTOWER, A.W.; MASCOLA, L. Association of sporadic listeriosis with consuption of uncooked hot dogs and undercooked chicken. Lancet, London, v.2, n.8614, p.779782, 1988.

SHANK, F.R.; ELLIOT, E.L.; WACHSMUTH, I.K.; LOSIKOFF, M.E. US position on Listeria monocytogenes in foods. Food Control, v.7, n.4, p.229-234, 1996.

SILVA, W.P., LIMA A. S., GANDRA, E. A., ARAÚJO, M. R., MACEDO, M.R.P., DUVAL, E.H. Listeria spp. no processamento de lingüiça frescal em frigoríficos de Pelotas, RS, Brasil. Ciência Rural, Santa Maria, v.34, n.3, p.911-916, mai-jun, 2004.

TERATANAVAT, R.; HOOKER, N.H. Understanding the characteristics of US meat and poultry recalls: 19942002. Food Control, v.15, n.5, p.359-367, 2004.

TOMPKIN, R.B. Control of Listeria monocytogenes in the food-processing environment. Journal Food Protec- tion, Ames, v.65, n.4, p.709-725, 2002.

UYTTENDAELE, M.; DE TROY, P.; DEBEVERE, J. Incidence of Listeria monocytogenes in different types of meat products on the Belgian retail market. International Journal of Food Microbiology, Amsterdam, v.53, n.1, p.75-80, 1999.

VAN COILLIE, E.; WERBROUCK, H.; HEYNDRICKX, M.; HERMAN, L.; RIJPENS, N. Prevalence and typing of Listeria monocytogenes in ready-to-eat food products on the Belgian market. Journal of Food Protection, Ames, v.67, n.11, p.2480-2487, 2004.

VITAS, A.I.; GARCIA-JALON, V.A. Ocurrence of Listeria monocytogenes in fresh and processed foods in Navarra (Spain). International Journal of Food Microbiology, Amsterdam, v.90, n.3, p.349-356, 2004.

VORSTER, S.M.; GREEBE, R.P.; NORTJE, G.L. The incidence of Listeria in processed meat of South Africa. Journal of Food Protection, Ames, v.56, n.22, p.169172, 1993.

WALLACE, F.M.; CALL, J.E.; PORTO, A.C.S.; COCOMA, G.J.; ERRC SPECIAL PROJECT TEAMS T.; LUCHANSKY, J.B. Recovery rate of Listeria monocytogenes from commercially prepared frankfurters during extended refrigerated storage. Journal of Food Protection, Ames, v.66, n.4, p.584-591, 2003.

WENGER, J.D.; SWAMINATHAN, B.; HAYES, P.S; GREEN, S.S.; PRATT, M.; PINNER, R.W.; SCHUCHAT, A.; BROOME, C.V. Listeria monocytogenes contamination of turkey franks: evaluation of a production facility. Journal of Food Protection, Ames, v.53, n.12, p.10151019, 1990.

WHO - World Health Organization. Working Group. Foodborne listeriosis, Bulletin WHO, v.66, n.4, p.421$428,1988$.

WILSON, I.G. Ocurrence of Listeria species in ready to eat foods. Epidemiology and Infection, Cambridge, v.115, n.3, p.519-526, 1995. 